\title{
An application of a glassy carbon electrode and a glassy carbon electrode modified with multi-walled carbon nanotubes in electroanalytical determination of oxycarboxin
}

\author{
Andrzej Leniart $^{1}$ - Mariola Brycht ${ }^{1} \cdot$ Barbara Burnat $^{1} \cdot$ Sławomira Skrzypek $^{1}$
}

Received: 26 September 2017 / Revised: 10 December 2017 / Accepted: 2 January 2018 / Published online: 18 January 2018

(C) The Author(s) 2018. This article is an open access publication

\begin{abstract}
An electrochemical procedure for the quantitative determination of oxycarboxin at a glassy carbon electrode (GCE) and a glassy carbon electrode modified with multi-walled carbon nanotubes (GCE/MWCNTs) based on square wave adsorptive stripping voltammetry (SWAdSV) is presented for the first time. The effect of an amplitude $\left(E_{\mathrm{SW}}\right)$, a frequency $(f)$, a step potential $\left(\Delta E_{\mathrm{s}}\right)$, an accumulation potential $\left(E_{\text {acc }}\right)$ and time $\left(t_{\text {acc }}\right)$, and equilibration time $\left(t_{\text {eq }}\right)$ was investigated. The best analytical signal was obtained in the medium of sulfuric acid on both electrodes. Under optimal analytical conditions, the linear ranges of $O x y$ concentrations $8.0 \times 10^{-6}-5.0 \times 10^{-5} \mathrm{~mol} \mathrm{~L}^{-1}$ with limit of detection of $2.0 \times 10^{-6} \mathrm{~mol} \mathrm{~L}^{-1}$ for bare GCE and $6.0 \times 10^{-6}-9.0 \times$ $10^{-5} \mathrm{~mol} \mathrm{~L}^{-1}$ with limit of detection of $1.1 \times 10^{-6} \mathrm{~mol} \mathrm{~L}^{-1}$ for GCE/MWCNTs were obtained. To investigate the utility of the proposed method for the determination of oxycarboxin in real samples, a quantitative determination of $O x y$ was performed in spiked river water samples. The electrode processes of oxycarboxin oxidation were studied by cyclic voltammetry (CV) at both electrodes. The surface characterization of bare GCE and GCE/MWCNTs was evaluated with an atomic force microscopy (AFM) and a scanning electron microscopy (SEM).
\end{abstract}

Keywords Oxycarboxin · Glassy carbon electrode $\cdot$ Multi-walled carbon nanotubes $\cdot$ Atomic force microscopy $\cdot$ Voltammetry River water

\section{Introduction}

Oxycarboxin (Oxy, 5,6-dihydro-2-methyl-1,4-oxathiin-3carboxanilide-4,4-dioxide, Fig. 1) is a fungicide belonging to the first-generation succinate dehydrogenase inhibitors (SDHIs). The mode of action of SDHIs is an inhibition of the succinate reductase activity of the complex II in the respiration chain and a distortion of the electron transport derived from succinate directly to the ubiquinone [1-4].

$O x y$ is very effective in the control of plant diseases caused by Basidiomycetes, such as smuts of cereals, rusts of grasses, pines, rose family, coffee, etc. It is used as a chemical agent for

Andrzej Leniart, Mariola Brycht, Barbara Burnat ISE Member

Andrzej Leniart

andrzej.leniart@chemia.uni.lodz.pl

1 Faculty of Chemistry, Department of Inorganic and Analytical Chemistry, University of Lodz, Tamka 12, 91-403 Lodz, Poland seed treatments of wheat, barley, peanut, flax, and cotton prior to planting [4-6]. Long-term ingesting of food and drinking water contaminated with the oxycarboxin, as well as dermal contact with $O x y$-treated seeds and soils, and inhalation of this pesticide vapor causes toxic effects, primarily damaging liver and kidney. Due to the harmful effects of oxycarboxin on living organisms, it is very important to develop simple and sensitive methods to identify and determine the concentration of $O x y$ in real samples. There are only a few publications devoted to the determination of oxycarboxin, and to the best of our knowledge, spectrophotometric method [7] and chromatographic techniques, such as thin-layer chromatography [8], gas chromatography [9], and high-speed liquid chromatography [10], were reported. Determination of oxycarboxin in spiked water samples was made by high-speed liquid chromatography in the concentration range of $3.7 \times 10^{-6} \mathrm{~mol} \mathrm{~L}^{-1}$ to $3.0 \times 10^{-4} \mathrm{~mol} \mathrm{~L}^{-1}$ [10]. These methods usually require expensive equipment, and they are time-consuming. An alternative to them are electrochemical techniques, which are characterized by satisfactory sensitivity, lower apparatus cost, and 
<smiles>CC1=C(C(=O)Nc2ccccc2)S(=O)(=O)CCO1</smiles>

Fig. 1 Chemical structure of $O x y$

simpler and faster operation. The most commonly used as working electrodes in electroanalytical chemistry are carbonbased electrodes, such as graphite [11-13], glassy carbon [14, $15]$, or carbon paste electrodes $[16,17]$. In order to improve the sensitivity and detection limit of the bare carbon-based electrodes, the modification of their surfaces can be performed with nanomaterials, such as for example graphene [18-22], carbon nanotubes [23-26], metal nanoparticles [21, 27, 28], etc. Nanomaterials exhibit extraordinary electrical and physical properties, and they are very often used for the electrode surface modifications.

The purpose of the present work was to develop an electroanalytical procedure for the quantitative determination of oxycarboxin at the glassy carbon electrode (GCE) and the glassy carbon electrode modified with multiwalled carbon nanotubes (GCE/MWCNTs). In this study, the square wave voltammetry (SWV) and the square wave adsorptive stripping voltammetry (SWAdSV) were used. The practical usefulness of the procedure was demonstrated by the determination of the fungicide $O x y$ in spiked Warta River water samples.

\section{Experimental}

\section{Chemicals and solutions}

All solutions were prepared from analytical grade chemicals, unless otherwise mentioned, in triply distilled water. Analytical standard of oxycarboxin (Oxy, CAS No. 5259-881, PESTANAL $®)$ was purchased from Sigma-Aldrich (Poznań, Poland). A stock solution of $O x y(1.0 \times$ $10^{-3} \mathrm{~mol} \mathrm{~L}^{-1}$ ) was freshly prepared in $25 \mathrm{~mL}$ volumetric flask by dissolving $6.7 \pm 0.1 \mathrm{mg}$ of the pure powder of $O x y$ in an acetone-water mixture $(1: 1, v / v)$ and kept in a refrigerator for up to 4 days. Britton-Robinson buffer solutions (BRBS) in a $\mathrm{pH}$ range from 2.0 to 7.0 were prepared from a starting mixture comprising $0.04 \mathrm{~mol} \mathrm{~L}^{-1}$ phosphoric acid $(85 \%$, POCh SA, Gliwice, Poland), $0.04 \mathrm{~mol} \mathrm{~L}^{-1}$ boric acid (POCh SA, Gliwice, Poland), and $0.04 \mathrm{~mol} \mathrm{~L}^{-1}$ acetic acid (99.5\%, POCh SA, Gliwice, Poland) by adding an appropriate amount of $0.2 \mathrm{~mol} \mathrm{~L}^{-1}$ sodium hydroxide (POCh SA, Gliwice, Poland) solution. Citrate buffer solutions (CBS) over a $\mathrm{pH}$ range of 1.0-2.5 were obtained by adding an adequate amount of $0.1 \mathrm{~mol} \mathrm{~L}^{-1}$ trisodium citrate dihydrate solution into
$0.1 \mathrm{~mol} \mathrm{~L}^{-1}$ hydrochloric acid. Citrate-phosphate buffer solutions (CPBS) in a pH range from 2.2 to 2.6 were obtained by adding an appropriate amount of $0.2 \mathrm{~mol} \mathrm{~L}^{-1}$ disodium hydrogen phosphate solution into $0.1 \mathrm{~mol} \mathrm{~L}^{-1}$ citric acid. Sulfuric acid solutions $\left(\mathrm{H}_{2} \mathrm{SO}_{4}\right)$ over a range of $0.1-1.0 \mathrm{~mol} \mathrm{~L}^{-1}$ were diluted from concentrated acid $(95 \%$, POCh SA, Gliwice, Poland).

\section{Apparatus}

Voltammetric measurements including cyclic voltammetry (CV), SWV, and SWAdSV were performed using an EmStat USB potentiostat (Palm Instruments B.V., the Netherlands) controlled by PSTrace software (General Purpose Electrochemical System, version 4.2.2.) in conjunction with an M164 electrode stand (MTM Anko Instruments, Kraków, Poland). All measurements were carried out at room temperature $\left(22 \pm 1^{\circ} \mathrm{C}\right)$ in the classical voltammetric cell consisting of three electrodes. The silver/silver chloride electrode in $3 \mathrm{~mol} \mathrm{~L}^{-1} \mathrm{KCl}$ solution (Mineral, Poland) was used as reference electrode. All potentials in this paper are given versus this reference electrode $\left(E^{0}=0.210 \mathrm{~V}\right.$ vs. NHE). A platinum wire $(99.99 \%$, Mennica Państwowa S.A., Warszawa, Poland) was used as auxiliary electrode. The measurements were carried out using two working electrodes, namely the glassy carbon electrode (GCE, L-Chem, Olomouc-Holice, the Czech Republic) inserted in a polyether ether ketone (PEEK) body with an inner diameter of $3 \mathrm{~mm}$ and the glassy carbon electrode modified with multi-walled carbon nanotubes (GCE/MWCNTs).

An ultrasonic homogenizer (SONOPULS HD 2200, Bandelin, Germany) was used in order to obtain MWCNTs suspensions.

The surface characterization of bare GCE and GCE modified with MWCNTs was evaluated with an atomic force microscope (AFM Dimension Icon, Bruker, Santa Barbara, CA, USA) operated in tapping mode by NanoScope software (version 9.0). Scanning probe model TESPA V2 (Bruker, Santa Barbara, CA, USA) with a $125-\mu \mathrm{m}$ nominal long silicon cantilever, spring constant of $42 \mathrm{~N} \mathrm{~m}^{-1}$, and a resonance frequency of $320 \mathrm{kHz}$ was used. The measurement parameters were as follows: a target amplitude of $31 \mathrm{~nm}$, a set-point amplitude of $20 \mathrm{~nm}$, the operating frequency of $348-349 \mathrm{kHz}$, and the scanning rate of $0.81 \mathrm{~Hz}$. The surface parameters were determined on the basis of AFM data using NanoScope Analysis software (version 1.4).

The surface morphology of bare GCE and GCE/ MWCNT was evaluated with a scanning electron microscope (SEM, Nova NanoSEM 450, FEI) using a through lens detector (TLD) at a beam energy of $15 \mathrm{kV}$. For control and analysis, the xT microscope Server/Control software was used. 


\section{Preparation of working electrodes}

The surface of GCE was manually polished on a polishing cloth (LAM PLAN S.A., Gaillard, France) with $\mathrm{Al}_{2} \mathrm{O}_{3}$ suspension $(0.3 \mu \mathrm{m}$, ATM GMBH, Germany), cleaned in an ultrasonic bath for $5 \mathrm{~min}$, rinsed with triple distilled water, and dried with argon.

The GCE/MWCNTs electrodes were prepared by dropping $4 \mu \mathrm{L}$ of the following suspensions of multi-walled carbon nanotubes (MWCNTs purified to more than $95 \% \mathrm{C}$ with a diameter of 6-9 nm and length of $5 \mu \mathrm{m}$, Sigma-Aldrich, Poznań, Poland) on the cleaned surface of GCE: 0.01, 0.05, $0.1,0.2$, and $0.5 \mathrm{mg} \mathrm{mL}^{-1}$ of MWCNTs dispersed in dimethylformamide (DMF, 99.5\%, POCh SA, Gliwice, Poland). The modified electrodes were then left to allow the evaporation of the solvent at room temperature.

\section{Voltammetric procedure}

Before each series of measurements, electrochemical activation and cleaning of working electrodes were performed in $0.1 \mathrm{~mol} \mathrm{~L}^{-1}$ sulfuric acid using the cyclic voltammetric sweeps in the range between -0.45 and $+1.65 \mathrm{~V}$ with a scan rate of $100 \mathrm{mV} \mathrm{s}^{-1}$ until stable voltammograms were obtained. Next, working electrode was washed with triple-distilled water, dried with argon, and transferred to the voltammetric cell with the analyzed working solution. CV, SWV, and SWAdSV were employed to investigate the electrochemical behavior and the quantification of $O x y$. The blank voltammograms were registered in the solution consisting of $9 \mathrm{~mL}$ of the supporting electrolyte with $1 \mathrm{~mL}$ of acetone-water mixture $(1: 1, v / v)$. CV investigations and optimization of the parameters of SWV and SWAdSV (the supporting electrolyte, the frequency, the amplitude, the step potential, the accumulation potential, and time) were carried out in the solution consisting of $9 \mathrm{~mL}$ of the supporting electrolyte with $1 \mathrm{~mL}$ of a stock solution of $O x y$ $\left(1.0 \times 10^{-3} \mathrm{~mol} \mathrm{~L}^{-1}\right) . \mathrm{CV}$ characteristics were registered in the potential range from +1.0 to $+1.6 \mathrm{~V}$ for GCE and from +1.0 to $+1.45 \mathrm{~V}$ for GCE/MWCNTs with different scan rates from 50 to $400 \mathrm{mV} \mathrm{s}^{-1}$, whereas SWV and SWAdSV voltammograms were registered in the potential range from +0.6 to + $1.8 \mathrm{~V}$ for both electrodes. Electroanalytical determinations of $O x y$ with the utilization of optimal parameters were performed in the solution consisting of $9 \mathrm{~mL}$ of the supporting electrolyte with appropriate volumes of stock solution of $O x y$ and acetone-water mixture.

\section{Spiked river water samples preparation}

For testing river water, samples were obtained from Warta River (Poland). The sample of river water without further pretreatment and purification was stored at $4.0^{\circ} \mathrm{C}$ in a refrigerator and analyzed within 3 days after sampling. The spiked sample of river water was prepared via transferring of $5 \mathrm{~mL}$ of a stock solution of $O x y\left(1.0 \times 10^{-3} \mathrm{~mol} \mathrm{~L}^{-1}\right)$ to a $50-\mathrm{mL}$ volumetric flask, and next, the flask was filled up to the mark with the river water. In order to study the possible interferences caused by river water, the SWAdSV curve of the blank was recorded in the solution consisting of $9 \mathrm{~mL}$ of the supporting electrolyte $\left(0.1 \mathrm{~mol} \mathrm{~L}^{-1}\right.$ sulfuric acid for GCE and $0.5 \mathrm{~mol} \mathrm{~L}^{-1}$ sulfuric acid for GCE/MWCNTs) with $1 \mathrm{~mL}$ of the river water. $O x y$ in the spiked samples of river water was analyzed using the standard addition method. The procedure for determination of $O x y$ was as follows: $1 \mathrm{~mL}$ of the spiked river water was added to the electrochemical cell containing $9 \mathrm{~mL}$ of supporting electrolyte $\left(0.1 \mathrm{~mol} \mathrm{~L}^{-1}\right.$ sulfuric acid for GCE and $0.5 \mathrm{~mol} \mathrm{~L}^{-1}$ sulfuric acid for GCE/MWCNTs), and the SWAdSV voltammogram was recorded. Then, three subsequent portions $(0.15 \mathrm{~mL}$ each for GCE and $0.20 \mathrm{~mL}$ each for GCE/MWCNTs) of a stock solution of oxycarboxin were added to the same electrochemical cell (the concentrations of Oxy corresponding to the additives were as follows: $1.48 \times$ $10^{-5}, 2.91 \times 10^{-5}$, and $4.31 \times 10^{-5} \mathrm{~mol} \mathrm{~L}^{-1}$ for GCE and $1.96 \times 10^{-5}, 3.85 \times 10^{-5}, 5.66 \times 10^{-5} \mathrm{~mol} \mathrm{~L}^{-1}$ for GCE/ MWCNTs). The SWAdSV voltammograms were recorded after each addition. The determination of oxycarboxin in spiked river water samples was repeated four times.

\section{Results and discussion}

\section{Topographic characteristics of bare GCE and GCE/MWCNT electrodes}

The determination of the amount of carbon nanotube suspension deposited on the surface of the GCE was performed in such a way that they form compact and uniform layer. For this purpose, a characterization of bare and modified GCE surfaces with different amounts of carbon nanotubes was done by AFM and SEM. AFM measurements were performed in tapping mode with simultaneous registration of height, amplitude, and phase for three independent samples. For each sample, three randomly selected scanning areas $(5 \mu \mathrm{m} \times 5 \mu \mathrm{m})$ were scanned. AFM and SEM images for chosen electrodes, namely GCE, GCE/MWCNTs $\mathrm{M}_{(0.01)}$, GCE/MWCNTs $\mathrm{M}_{(0.2)}$, and GCE/MWCNTs $(0.5)$, are shown in Fig. 2, where 0.01, 0.2, and 0.5 subscripts denote concentration of carbon nanotubes in suspension. AFM phase images (results not shown) indicated that the surfaces do not contain any impurities. As can be seen in both SEM and AFM images, in the case of the carbon nanotube suspensions at concentrations ranging between 0.01 and $0.2 \mathrm{mg} \mathrm{mL}^{-1}$, the GCE surfaces were not covered entirely by MWCNTs (places of the bare electrode surface are clearly visible). It was found that the compact, uniform, and reproducible layer of MWCNTs covering the entire surface of GCE were obtained for MWCNT suspension at concentration 


\section{a}

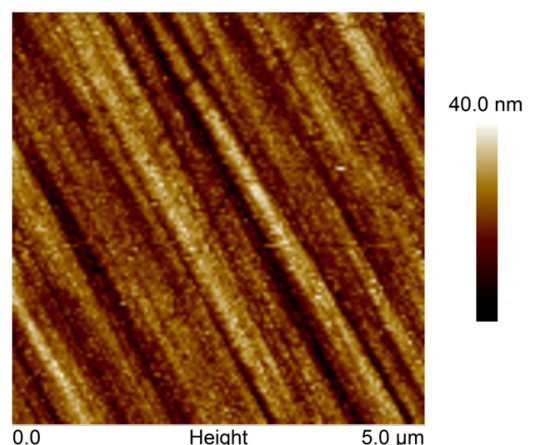

b

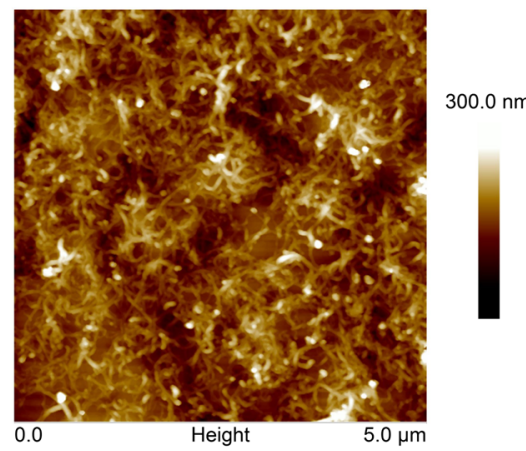

C

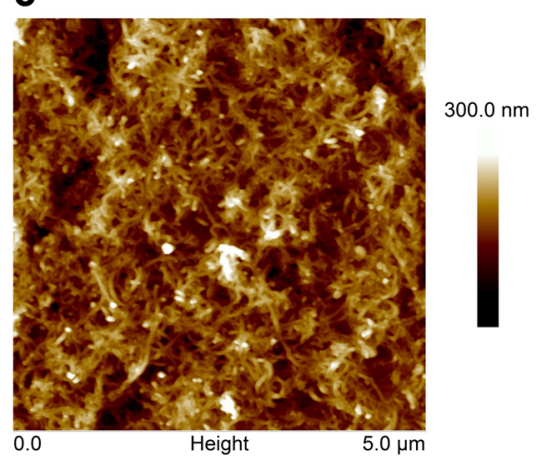

d

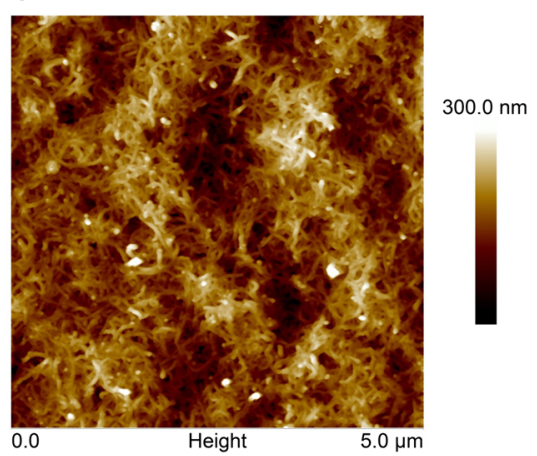

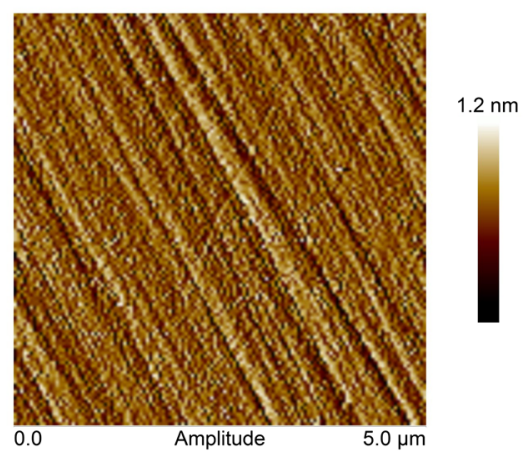
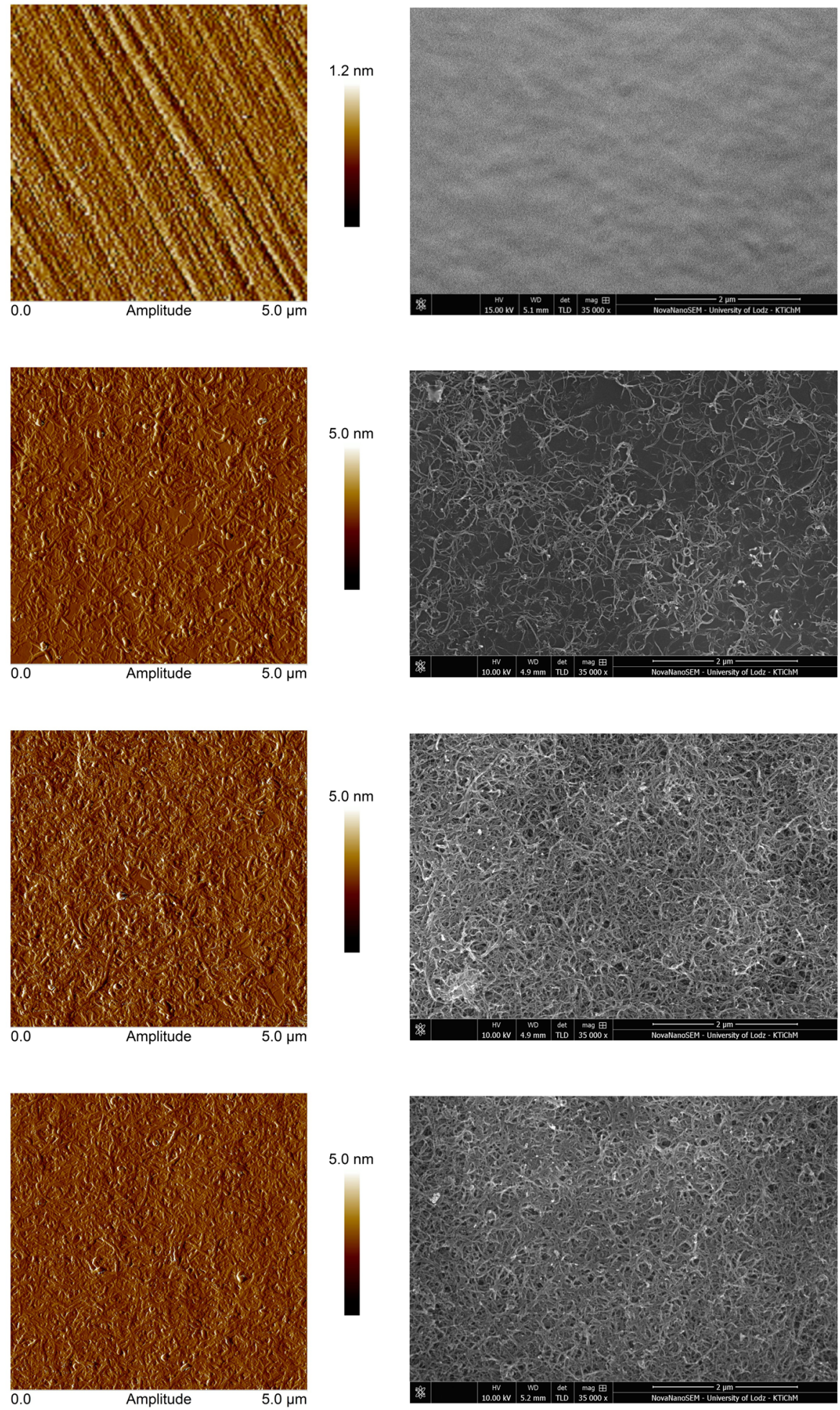

Fig. 2 AFM and SEM images for the bare GCE (a), GCE/MWCNTs $\mathrm{M}_{(0.05)}(\mathbf{b}), \operatorname{GCE} / \operatorname{MWCNTs}_{(0.2)}(\mathbf{c})$, and GCE/MWCNTs $(0.5)(\mathbf{d})$

of $0.5 \mathrm{mg} \mathrm{mL} \mathrm{m}^{-1}$. Due to the fact that nanotubes are elastic, they are bending, tangling, stretching, or twisting without breaking as is clearly visible in the AFM amplitude images.

Additionally, the surface topography parameters, such as the surface roughness $(\mathrm{Rq}, \mathrm{Ra})$ and the surface area difference
(SAD), were determined from the AFM data using Nanoscope Analysis software. The Rq parameter is defined as the root mean square average of height deviations taken from the mean image data plane; $\mathrm{Ra}$ is calculated as arithmetic average of the absolute values of the surface height deviations measured 
Table 1 The surface topography parameters obtained from scanning areas of $5 \mu \mathrm{m} \times 5 \mu \mathrm{m}$ for each electrode

\begin{tabular}{|c|c|c|c|}
\hline Electrode & $\mathrm{Rq} / \mathrm{nm}$ & $\mathrm{Ra} / \mathrm{nm}$ & $\mathrm{SAD} / \%$ \\
\hline GCE & 5.9 & 4.6 & 1.2 \\
\hline GCE/MWCNTs $_{(0.01)}$ & 22.5 & 16.0 & 15.0 \\
\hline GCE/MWCNTs $_{(0.05)}$ & 28.9 & 22.3 & 29.8 \\
\hline $\mathrm{GCE} \mathrm{MWCNTs}_{(0.1)}$ & 32.4 & 25.5 & 36.6 \\
\hline $\mathrm{GCE} \mathrm{MWCNTs}_{(0.2)}$ & 34.2 & 26.7 & 38.2 \\
\hline $\mathrm{GCE}_{\mathrm{MWCNTs}} \mathrm{MW.5}_{(0)}$ & 44.5 & 35.1 & 51.0 \\
\hline
\end{tabular}

from the mean plane, and SAD is described as difference between the images of three-dimensional surface area and two-dimensional projected surface area [29].

As may be noted for the data presented in Table 1, the surface parameter values were increased when a greater amount of MWCNTs was deposited on GCE. The Rq and Ra were increased almost eightfold and SAD more than 40 times for GCE/MWCNTs $s_{(0.5)}$ when compared to bare GCE. On the basis of the AFM and SEM results, GCE modified with MWCNT suspension at concentration of $0.5 \mathrm{mg} \mathrm{mL}^{-1}$ was chosen as a working electrode and denotes further as GCE/ $\operatorname{MWCNTs}_{(0.5)}$.

\section{Selection of the supporting electrolyte and its $\mathrm{pH}$}

The composition and $\mathrm{pH}$ of the supporting electrolyte play a major role in the electrochemical processes. In the case of the voltammetric techniques, they influence the curve shape, the height, and the width, as well as the position of the peak. When the selection of composition and $\mathrm{pH}$ of supporting electrolyte is performed incorrectly, it can happen that the electrochemical reactions do not occur and analysis will not be possible. For this reason, the effect of the supporting electrolyte and its $\mathrm{pH}$ on the voltammetric response of oxycarboxin was investigated using the square-wave voltammetry (SWV). Thus, Britton-Robinson buffer solutions (BRBS) in the $\mathrm{pH}$ range from 2.0 to 7.0 , citrate buffer solutions (CBS) over a $\mathrm{pH}$ range of 1.0-2.5, citrate-phosphate buffer solutions (CPBS) in a pH range from 2.2 to 2.6, and different concentrations of sulfuric acid in a range between 0.1 and $1.0 \mathrm{~mol} \mathrm{~L}^{-1}$ containing $1.0 \times 10^{-4} \mathrm{~mol} \mathrm{~L}^{-1}$ of oxycarboxin were tested.

As can be seen in Fig. 3, the shape of SW voltammograms depends strongly on the composition and $\mathrm{pH}$ of supporting electrolyte. Only one anodic peak connected with an electrooxidation of oxycarboxin at potential about $+1.3 \mathrm{~V}$ was visible on $\mathrm{SW}$ voltammograms except for BRBS at GCE/MWCNTs $(0.5)$. In the case of BrittonRobinson buffer solutions at GCE, a slight shift in the peak potentials towards less positive values from $1.27 \mathrm{~V}$ (pH 2.0) to $1.13 \mathrm{~V}(\mathrm{pH} \mathrm{5)}$ and the progressive decrease of the peak currents was observed with the increase of $\mathrm{pH}$ values. It was found that the oxycarboxin oxidation peak was not observed at $\mathrm{pH} 6.0$ and higher $\mathrm{pH}$ values. SW voltammograms recorded on GCE/MWCNTs $\mathrm{M}_{(0.5)}$ in BRBS
Fig. 3 SW voltammograms obtained on bare GCE and GCE/ $\operatorname{MWCNTs}_{(0.5)}$ in BrittonRobinson buffer solutions and sulfuric acid solutions containing $1.0 \times 10^{-4} \mathrm{~mol} \mathrm{~L}^{-1}$ of oxycarboxin. The measurement parameters: amplitude of $40 \mathrm{mV}$, frequency of $50 \mathrm{~Hz}$, step potential of $2 \mathrm{mV}$, and equilibration time of $5 \mathrm{~s}$
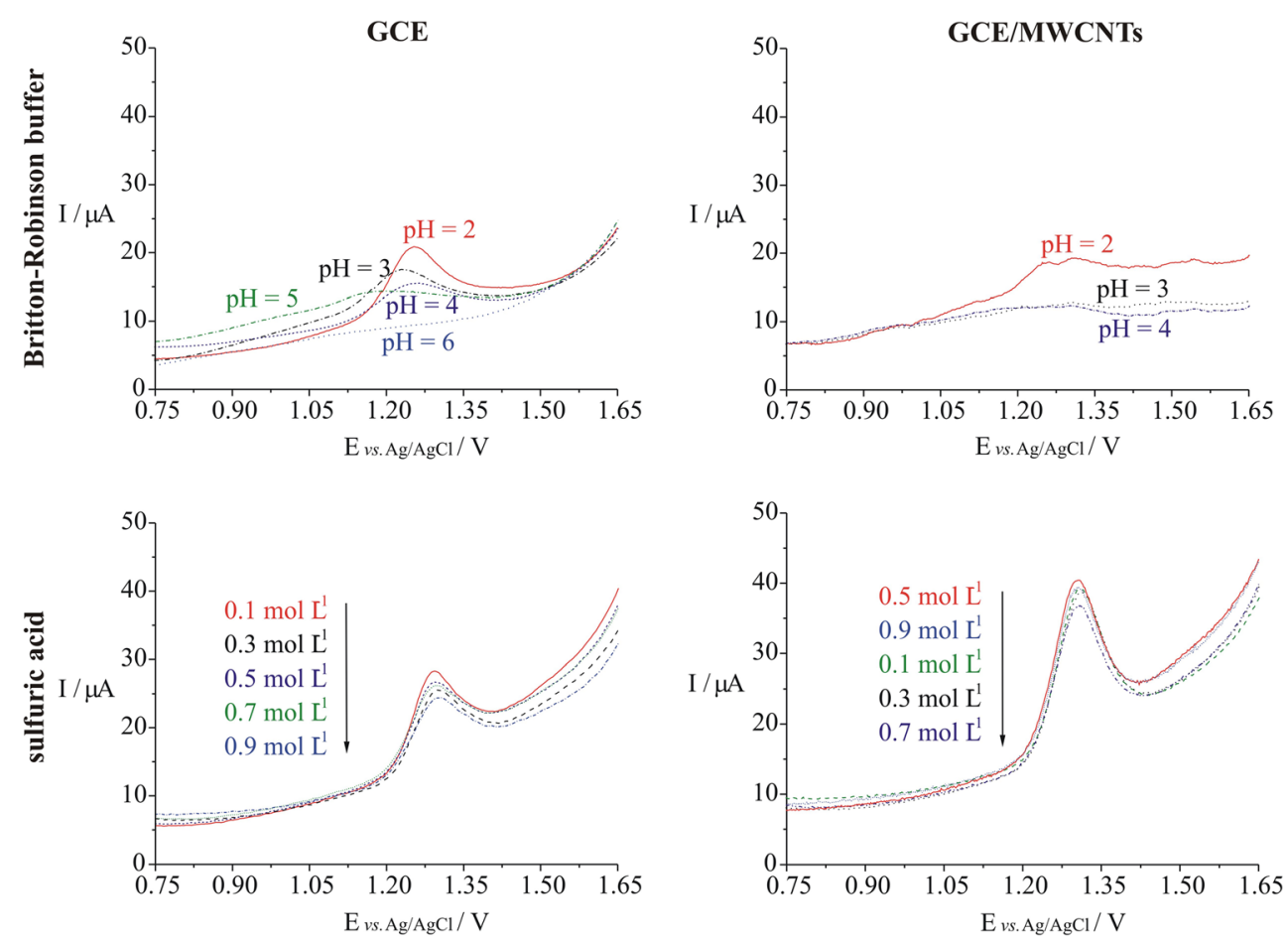
Fig. 4 Cyclic voltammograms obtained on bare GCE (a) and GCE/MWCNTs $(0.5)(\mathbf{b})$ in sulfuric acid solutions containing $1.0 \times$ $10^{-4} \mathrm{~mol} \mathrm{~L}^{-1}$ of oxycarboxin. The dependences of $I$ versus $\nu^{1 / 2}$ and $\log I$ versus $\log \nu$ for GCE (c) and $\operatorname{GCE} \operatorname{MWCNTs}_{(0.5)}(\mathbf{d})$
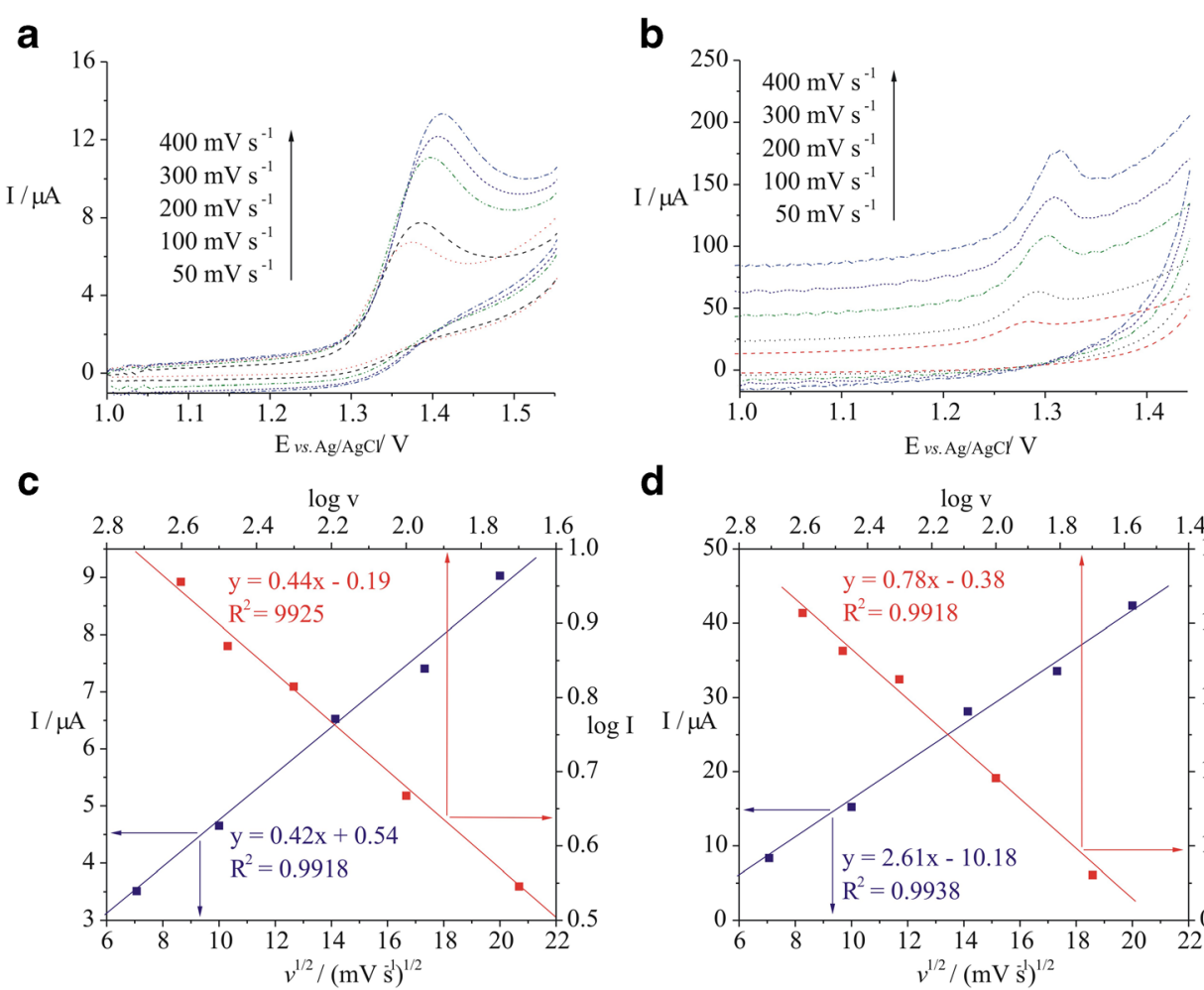

d

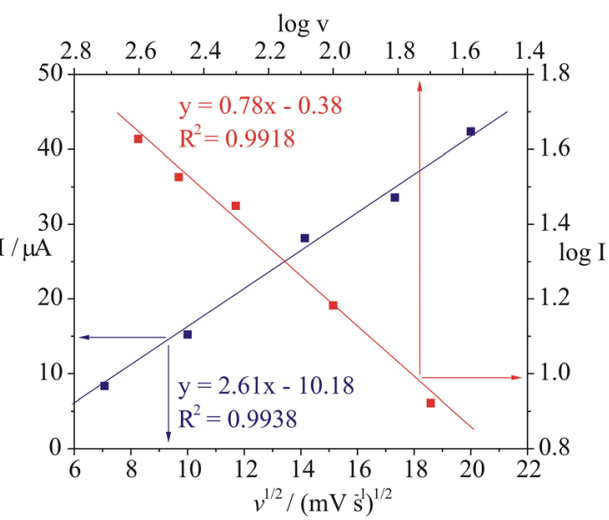

were strongly distorted and unsuitable for the further analysis. Due to the fact that the highest signal descended from oxycarboxin was observed at $\mathrm{pH} 2.0$ of BRBS, other supporting electrolytes were tested on both working electrodes. In the case of CBS and CPBS, the experimental results (not presented) were different than expected on both electrodes. The analytical signals were changeable and inconsistent with one another. Whereas, well-shaped and higher anodic peak was observed in sulfuric acid solutions for bare and modified electrodes, nevertheless, the peak currents not shown any dependence of the sulfuric acid concentration for GCE/MWCNTs $(0.5)$. It was found from these results that the suitable supporting electrolyte for voltammetric determination of oxycarboxin is $\mathrm{H}_{2} \mathrm{SO}_{4}$. Sulfuric acid at a concentration of 0.1 and $0.5 \mathrm{~mol} \mathrm{~L}^{-1}$ for GCE and GCE/MWCNTs ${ }_{(0.5)}$, respectively, was chosen as the supporting electrolyte solution for further studies.

\section{Electrochemical behavior of oxycarboxin}

Cyclic voltammetry (CV) is a technique which gives information about the occurring electrode processes. Therefore, the effect of a scan rate $(\nu)$ in the range of $50-400 \mathrm{mV} \mathrm{s}^{-1}$ on the height and shape of cyclic voltammograms was investigated at GCE and GCE/MWCNTs ${ }_{(0.5)}$ in the supporting electrolyte solutions containing $1.0 \times 10^{-4} \mathrm{~mol} \mathrm{~L}^{-1}$ of oxycarboxin.

As shown in Fig. 4 for both electrodes, one anodic peak connected with oxidation of oxycarboxin was observed without any cathodic peaks in the reversed scan in the investigated potential range. This suggests that oxidation process of $O x y$ is irreversible. The confirmation of this is the shift of the anodic peak potentials towards more positive values with the increase of the scan rate and the linear dependence of the peak current intensity versus square root of the scan rate $\left(\nu^{1 / 2}\right)$. Additionally, the linear relationships between the logarithm

Table 2 Optimized SWAdSV parameter values for the determination of oxycarboxin

\begin{tabular}{lccccc}
\hline & $E_{\mathrm{SW}} / \mathrm{mV}$ & $f / \mathrm{Hz}$ & $\Delta E_{\mathrm{s}} / \mathrm{mV}$ & $E_{\mathrm{acc}} / \mathrm{V}$ & $t_{\mathrm{acc}} / \mathrm{s}$ \\
\hline Examined range & $10-100$ & $10-100$ & $1-10$ & & \\
& & & & $5-1.1$ & $5-100$ \\
Optimized parameters & 30 & 70 & 6 & 0.8 & 20 \\
GCE & 40 & 40 & 10 & 0.8 & 30 \\
GCE/MWCNTs $(0.5)$ & & & & 5 \\
\hline
\end{tabular}


Fig. 5 SWAdS voltammograms recorded in $0.1 \mathrm{~mol} \mathrm{~L}^{-1} \mathrm{H}_{2} \mathrm{SO}_{4}$ at GCE (a) and $0.5 \mathrm{~mol} \mathrm{~L}^{-1} \mathrm{H}_{2} \mathrm{SO}_{4}$ at $\mathrm{GCE} / \mathrm{MWCNTs}_{(0.5)}(\mathbf{b})$ with increasing concentrations of oxycarboxin: (0) blank, (1) $6.0 \times$ $10^{-6}$, (2) $7.0 \times 10^{-6}$, (3) $8.0 \times$ $10^{-6}$, (4) $9.0 \times 10^{-6},(5) 1.0 \times$ $10^{-5}$, (6) $2.0 \times 10^{-5},(7) 3.0 \times$ $10^{-5}$, (8) $4.0 \times 10^{-5}$, (9) $5.0 \times$ $10^{-5}$, (10) $6.0 \times 10^{-5}$ (11) $7.0 \times$ $10^{-5}$, (12) $8.0 \times 10^{-5}$, and (13) $9.0 \times 10^{-5} \mathrm{~mol} \mathrm{~L}^{-1}$. Insets: corresponding calibration curves a

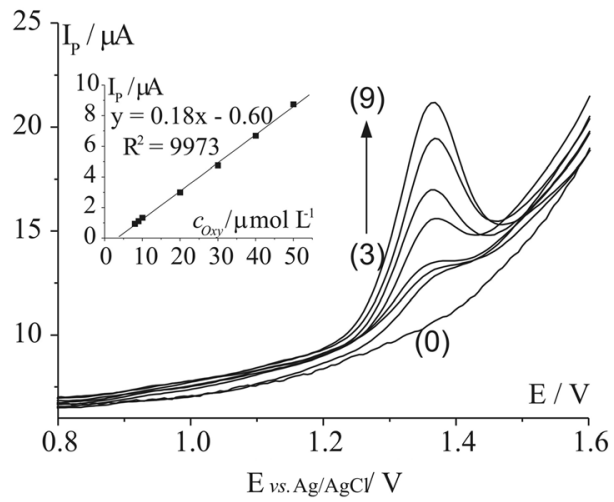

b

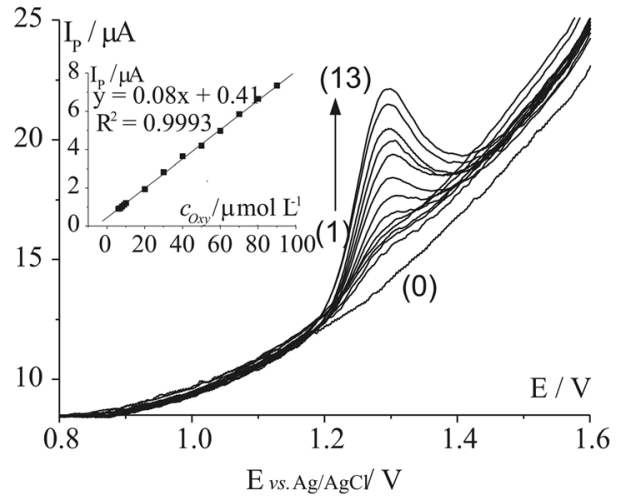

of the anodic peak current intensity $(\log I)$ and the logarithm of the scan rate $(\log \nu)$ gave slopes of 0.44 for GCE and 0.76 for $\mathrm{GCE} / \mathrm{MWCNTs}_{(0.5)}$. These values of slopes indicate that oxidation of $O x y$ at GCE is a diffusion-controlled process, while at $\mathrm{GCE} / \mathrm{MWCNTs}_{(0.5)}$, it is a diffusion-adsorption mixed controlled process. Based on the available literature data, oxycarboxin probably has several possible independent active centers (central sites) for its electrochemical oxidation. One of them, according to the literature data [30-32], can be a nitrogen atom. In acidic aqueous media, oxidation can be additionally combined with scission of the carbon-nitrogen bond. Another possibility is the oxidation at carbon atom in the oxathiin ring connected with opening of the ring and hydrolytically removal of an acetyl group. It should be emphasize that the determination of the electrode mechanism of oxycarboxin oxidation was not the purpose of this work and is beyond the scope of this research.

\section{Optimization of SWAdSV parameters}

The analytical signal in square wave adsorptive stripping voltammetry depends on various instrumental parameters, such as the amplitude $\left(E_{\mathrm{SW}}\right)$, the frequency $(f)$, the step potential $\left(\Delta E_{\mathrm{s}}\right)$, the accumulation potential $\left(E_{\mathrm{acc}}\right)$ and time $\left(t_{\mathrm{acc}}\right)$, and equilibration time $\left(t_{\mathrm{eq}}\right)$. The effect of all these parameters in sulfuric acid solutions at a concentration of $0.1 \mathrm{~mol} \mathrm{~L}^{-1}$ for GCE and $0.5 \mathrm{~mol} \mathrm{~L}^{-1}$ for GCE/MWCNTs ${ }_{(0.5)}$ containing $1.0 \times 10^{-4} \mathrm{~mol} \mathrm{~L}^{-1}$ oxycarboxin was investigated. The influence of the amplitude on the oxycarboxin response was investigated in a range from 10 to $100 \mathrm{mV}$. Initially, the peak current increased, reaching a maximum at 30 and $40 \mathrm{mV}$ for GCE and GCE/MWCNTs ${ }_{(0.5)}$, respectively, and then the peak current decreased slightly. Based on these results, the values of $E_{\mathrm{SW}}=30 \mathrm{mV}$ for $\mathrm{GCE}$ and $E_{\mathrm{SW}}=40 \mathrm{mV}$ for $\mathrm{GCE} /$ $\operatorname{MWCNTs}_{(0.5)}$ were chosen. The frequency was optimized in the range from 10 to $100 \mathrm{~Hz}$. The peak current increased linearly with increasing frequency value for both investigated electrodes. Frequency of 70 and $40 \mathrm{~Hz}$ for GCE and GCE/ $\operatorname{MWCNTs}_{(0.5)}$, respectively, was selected as optimum values. Next, the step potential was optimized in the range from 1 to $10 \mathrm{mV}$. Similarly as in the case of frequencies, the peak current increased gradually and continuously with an increase in step potential value. The best-shaped analytical signal was obtained for the step potential value of 6 and $10 \mathrm{mV}$ for GCE and $\mathrm{GCE}_{\mathrm{MWCNTs}} \mathrm{MW.5}$, respectively, and for this reason, these values were used for the further analytical applications. In the next steps, the influence of the accumulation potential and the accumulation time on the oxidation peak current of oxycarboxin was investigated. A maximum of the peak current was obtained at $E_{\mathrm{acc}}=+0.8 \mathrm{~V}$ and $t_{\mathrm{acc}}=20 \mathrm{~s}$ for GCE and
Table 3 The parameters obtained from linear least square regression for the quantitative determination of oxycarboxin at GCE and GCE/ $\operatorname{MWCNTs}_{(0.5)}$

\begin{tabular}{lll}
\hline & GCE & GCE/MWCNTs $(0.5)$ \\
\hline Concentration range $\left[\mathrm{mol} \mathrm{L}^{-1}\right]$ & $8.0 \times 10^{-6}-5.0 \times 10^{-5}$ & $6.0 \times 10^{-6}-9.0 \times 10^{-5}$ \\
Slope (b) $\left[\mathrm{A} \mathrm{L} \mathrm{mol}^{-1}\right]$ & 0.18 & 0.08 \\
$\mathrm{SDb}$ & $0.42 \times 10^{-2}$ & $0.77 \times 10^{-3}$ \\
Intercept (a) [A] & -0.60 & 0.41 \\
SDa & 0.12 & 0.03 \\
Determination coefficient & 0.9973 & 0.9993 \\
Number of points & 7 & 13 \\
LOD (mol L & $\left.2.0 \times 10^{-6}\right)$ & $1.1 \times 10^{-6}$ \\
LOQ (mol L & $\left.6.7 \times 10^{-6}\right)$ & $3.8 \times 10^{-6}$ \\
\hline
\end{tabular}


Table 4 The comparison of other electrochemical determinations using glassy carbon electrode modified with multi-walled carbon nanotubes

\begin{tabular}{lllll}
\hline Analyte & Method & Linear range $/ \mathrm{mol} \mathrm{L}^{-1}$ & LOD $/ \mathrm{mol} \mathrm{L}^{-1}$ & References \\
\hline Fipronil & Amperometric & $2.5 \times 10^{-5}-3.0 \times 10^{-4}$ & $4.7 \times 10^{-6}$ & {$[36]$} \\
Ellagic acid & Amperometric & $6.6 \times 10^{-7}-5.3 \times 10^{-5}$ & $1.9 \times 10^{-7}$ & {$[37]$} \\
Eriodictyol & DPV & $3.5 \times 10^{-8}-3.5 \times 10^{-5}$ & $1.1 \times 10^{-8}$ & {$[38]$} \\
Propham & SWV & $2.0 \times 10^{-6}-4.8 \times 10^{-5}$ & $3.6 \times 10^{-7}$ & {$[23]$} \\
Oxymetholone & SWV & $6.0 \times 10^{-8}-2.7 \times 10^{-7}$ & $4.1 \times 10^{-8}$ & {$[39]$} \\
Dinitramine & SWV & $4.0 \times 10^{-8}-1.4 \times 10^{-6}$ & $0.8 \times 10^{-8}$ & {$[40]$} \\
Resorcinol & SWV & $1.2 \times 10^{-6}-1.9 \times 10^{-4}$ & $4.9 \times 10^{-7}$ & {$[41]$} \\
Oxycarboxin & SWV & $6.0 \times 10^{-6}-9.0 \times 10^{-5}$ & $1.1 \times 10^{-7}$ & This work \\
\hline
\end{tabular}

$D P V$ differential pulse voltammetry, $S W V$ square wave voltammetry at $E_{\mathrm{acc}}=+0.8 \mathrm{~V}$ and $t_{\mathrm{acc}}=30 \mathrm{~s}$ for GCE/MWCNTs $(0.5)$. The last parameter was equilibration time, examined in the range from 5 to $30 \mathrm{~s}$. The equilibration time values of 15 and $5 \mathrm{~s}$ for GCE and GCE/MWCNTs ${ }_{(0.5)}$, respectively, were selected. The optimized SWAdSV parameters for both electrodes are collected in Table 2.

\section{Linearity, detection, and quantitation limit of developed method}

Quantitative determination of oxycarboxin was performed on both investigated electrodes using SWAdSV method under previously optimized parameters (Table 2). Figure 5 shows the SWAdSV voltammograms recorded at the GCE (Fig. 5a)

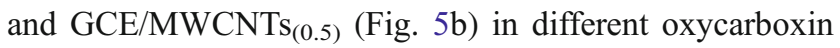
concentrations. It was found that the dependences were linear in the range of $8.0 \times 10^{-6}-5.0 \times 10^{-5} \mathrm{~mol} \mathrm{~L}^{-1}$ with a determination coefficient of 0.9973 for GCE (the inset in Fig. 5a) and $6.0 \times 10^{-6}-9.0 \times 10^{-5} \mathrm{~mol} \mathrm{~L}^{-1}$ with a determination coefficient of 0.9989 for GCE/MWCNTs $(0.5)$ (the inset in Fig. 5b).

The parameters obtained from the linear least square regressions for the investigated dependences are presented in

\section{GCE}

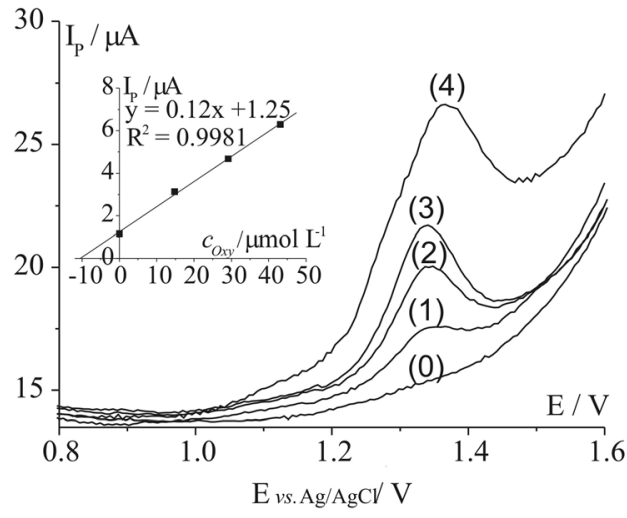

Fig. 6 SWAdSV voltammograms of determination of oxycarboxin in the spiked Warta River water samples using the standard addition method in (0) supporting electrolyte, (1) after addition of $1 \mathrm{~mL}$ of the spiked river water, and (2) after spiking of $0.15 \mathrm{~mL},(3)$ as (2) $+0.15 \mathrm{~mL},(4)$ as (3) +
Table 3. On the basis of the standard deviations of intercepts (SDa) and the slope (b) of the calibration curves, the limits of detection (LOD) and quantification (LOQ) were calculated for the five repetitions $(n=5)$ using the following formulas: $\mathrm{LOD}=3 \times \mathrm{SDa} / \mathrm{b}$ and $\mathrm{LOQ}=10 \times \mathrm{SDa} / \mathrm{b}$ [33-35]. LOD and LOQ obtained at GCE were $2.0 \times 10^{-6} \mathrm{~mol} \mathrm{~L}^{-1}$ and $6.7 \times$ $10^{-6} \mathrm{~mol} \mathrm{~L}^{-1}$, respectively, whereas the LOD and LOQ at GCE/MWCNTs $(0.5)$ were $1.1 \times 10^{-6}$ and $3.8 \times 10^{-6} \mathrm{~mol} \mathrm{~L}^{-1}$, respectively. The obtained LOD values in this paper are close to the LOD values of oxycarboxin determination of the other analytical techniques described in the literature, i.e., $1.12 \times$ $10^{-7} \mathrm{~mol} \mathrm{~L}^{-1}$ for spectrophotometry [7], $1.12 \times 10^{-5} \mathrm{~mol} \mathrm{~L}^{-1}$ for thin-layer chromatography [8], $1.87 \times 10^{-6} \mathrm{~mol} \mathrm{~L}^{-1}$ for gas chromatography [9], and $3.74 \times 10^{-6} \mathrm{~mol} \mathrm{~L}^{-1}$ for high-speed liquid chromatography [10]. Additionally, the precision (the coefficient of variation) and the accuracy for five repetitions at each concentration of oxycarboxin from the calibration curves for both investigated electrodes were determined. It was found that the precision and accuracy did not exceed $9 \%$ for GCE and GCE/MWCNTs $(0.5)$. Based on the above, it can be stated that the proposed electroanalytical method is adequate for the quantitative determination of oxycarboxin using both 
Table 5 Determination of oxycarboxin at GCE and GCE/ $\operatorname{MWCNTs}_{(0.5)}$ in the spiked Warta River water samples

\begin{tabular}{|c|c|c|c|c|c|}
\hline Sample number & $\begin{array}{l}\text { Oxy added } \\
\left(\mathrm{mol} \mathrm{L}^{-1}\right)\end{array}$ & $\begin{array}{l}\text { Oxy found } \\
\left(\mathrm{mol} \mathrm{L}^{-1}\right)\end{array}$ & $\begin{array}{l}\text { Oxy found average } \\
\left(\mathrm{mol} \mathrm{L}^{-1}\right)\end{array}$ & $\operatorname{RSD}(\%)$ & Recovery ${ }^{(b)}(\%)$ \\
\hline \multicolumn{6}{|l|}{ GCE } \\
\hline 1 & \multirow[t]{4}{*}{$1.00 \times 10^{-5}$} & $9.98 \times 10^{-6}$ & \multirow[t]{4}{*}{$(1.06 \pm 0.07) \times 10^{-5}$} & \multirow[t]{4}{*}{4.4} & 99.80 \\
\hline 2 & & $1.04 \times 10^{-5}$ & & & 104.42 \\
\hline 3 & & $1.09 \times 10^{-5}$ & & & 108.80 \\
\hline 4 & & $1.10 \times 10^{-5}$ & & & 109.92 \\
\hline \multicolumn{6}{|c|}{ GCE/MWCNTs $_{(0.5)}$} \\
\hline 1 & \multirow[t]{4}{*}{$1.00 \times 10^{-5}$} & $1.04 \times 10^{-5}$ & \multirow[t]{4}{*}{$(1.07 \pm 0.05) \times 10^{-5}$} & \multirow[t]{4}{*}{2.9} & 104.30 \\
\hline 2 & & $1.11 \times 10^{-5}$ & & & 110.50 \\
\hline 3 & & $1.10 \times 10^{-5}$ & & & 109.66 \\
\hline 4 & & $1.05 \times 10^{-5}$ & & & 105.30 \\
\hline
\end{tabular}

electrodes; however, the linear range for GCE/MWCNTs $\mathrm{M}_{(0.5)}$ is wider than for GCE. This makes it possible to determine both lower and higher concentrations of $O x y$ at GCE/ $\operatorname{MWCNTs}_{(0.5)}$ when compared to GCE.

Table 4 presents the comparison of results obtained for other organic compounds using glassy carbon electrode modified with multi-walled carbon nanotubes. As can be seen, the results obtained in this work for oxycarboxin using GCE/MWCNTs $\mathrm{MW.5}_{(0)}$, i.e., linear range and LOD value, are in good agreement with the results presented in the literature [23, 36-41].

\section{Determination of oxycarboxin in spiked river water samples}

To examine the suitability of the proposed SWAdSV method for the determination of oxycarboxin in real samples, the quantitative determination of $O x y$ in spiked river water taken from the Warta River was performed using the standard addition method. The SWAdSV voltammograms and the standard addition plots at both investigated electrodes are shown in Fig. 6.

On the basis of obtained data, the precision (RSD) and recovery of an oxycarboxin were determined. As can be seen from Table 5, RSD at each sample was at a level not exceeding $5 \%$ and recovery values were in the accepted range of 99.8 $110.5 \%$. It indicates that there was no important interference from the matrix of Warta River water, and the proposed method provided good accuracy for the quantitative determination of oxycarboxin in river water samples.

\section{Conclusions}

A glassy carbon electrode (GCE) and a glassy carbon electrode modified with multi-walled carbon nanotubes (GCE/ MWCNTs) were used for the electrochemical determination of oxycarboxin. On the basis of the examination of unmodified and modified GCE surfaces by AFM and SEM, it can be stated that GCE/MWCNTs surfaces are much more developed than GCE surface, and the compact, uniform, and reproducible layer of MWCNTs covering the entire surface of GCE were obtained for MWCNTs suspension at concentration of $0.5 \mathrm{mg} \mathrm{mL}^{-1}$. It was found that $O x y$ is oxidized on GCE and GCE/MWCNTs in the acidic medium. The best analytical signal was obtained in the sulfuric acid solutions. The cyclic voltammetric results indicate that the oxidation of $O x y$ is irreversible and that it is controlled by the diffusion at GCE and diffusion-adsorption mixed process at GCE/MWCNTs $(0.5)$. It was found that the proposed electrochemical procedures based on the square wave adsorptive stripping voltammetry technique for determination of $O x y$ are characterized by the limits of detection of $2.0 \times 10^{-6}$ and $1.1 \times 10^{-6} \mathrm{~mol} \mathrm{~L}^{-1}$ for the GCE and GCE/MWCNTs $(0.5)$, respectively. The developed procedures were successfully applied for the analysis of oxycarboxin in real samples (river water) with recoveries close to $100 \%$.

In summary, a simple, rapid, and precise electrochemical methods for the quantitative analysis of oxycarboxin using GCE and GCE/MWCNTs $(0.5)$ are proposed in this paper for the first time, and they represent an alternative in relation to the existing procedures.

Open Access This article is distributed under the terms of the Creative Commons Attribution 4.0 International License (http:// creativecommons.org/licenses/by/4.0/), which permits unrestricted use, distribution, and reproduction in any medium, provided you give appropriate credit to the original author(s) and the source, provide a link to the Creative Commons license, and indicate if changes were made.

\section{References}

1. Avenot HF, Michailides TJ (2010) Progress in understanding molecular mechanisms and evolution of resistance to succinate dehydrogenase inhibiting (SDHI) fungicides in phytopathogenic fungi. Crop Prot 29(7):643-651. https://doi.org/10.1016/j.cropro.2010. 02.019 
2. Dehne HW, Deising HB, Gisi U, Kuck KH, Russell PE, Lyr H (2011) Modern fungicides and antifungal compounds VI. DPG, Selbstverlag

3. McKay AH, Hagerty GC, Follas GB, Moore MS, Christie MS, Beresford RM (2011) New Zealand plant. PRO 64:119-124

4. Okorski A, Pszczółkowska A, Oszako T, Nowakowska JA (2015) Current possibilities and prospects of using fungicides in forestry. For Res Pap 76(2):191-206

5. Schmeling B, Kulka M (1966) Systemic fungicidal activity of 1.4oxathiane derivatives. Science 152(3722):659-660. https://doi.org/ 10.1126/science.152.3722.659

6. Worthing CR (1987) The pesticide manual: a world compendium. Thornton Heath, The British Crop Protection Council

7. Debska W, Gnusowski B, Zygmunt B (1979) Determination of oxycarboxin residues in medicinal plants. Analyst 104(1245): 1191-1194. https://doi.org/10.1039/an9790401191

8. Tripathi RK, Bhaktavatsalam G (1973) Silver nitrate-bromophenol blue and potassium permanganate-sulphuric acid as chromogenic reagents for the detection of carboxin and oxycarboxin in thin-layer chromatography. J Chromatogr 87(1):283-286. https://doi.org/10. 1016/S0021-9673(01)91552-3

9. Tafuri F, Patumi M, Businelli M, Marucchini C (1978) Determination of residues of Vitavax and Plantvax in grains. $\mathrm{J}$ Agric Food Chem 26(6):1344-1346. https://doi.org/10.1021/ jf60220a015

10. Wolkoff AW, Onuska FI, Comba ME, Larose RH (1975) Determination of 5,6-dihydro-2-methyl-1,4-oxathiin-3carboxanilide (vitavax) and two of its photoproducts by high speed liquid chromatography. Anal Chem 47(4):754-756. https://doi.org/ 10.1021/ac60354a050

11. Brycht M, Skrzypek S, Karadas N, Smarzewska S, Bozal-Palabiyik B, Ozkan SA, Uslu B (2015) Voltammetric behavior and determination of antidepressant drug paroxetine at carbon-based electrodes. Ionics 21(8):2345-2354. https://doi.org/10.1007/s11581-0151390-6

12. Dilgin DG, Karakaya S (2016) Differential pulse voltammetric determination of acyclovir in pharmaceutical preparations using a pencil graphite electrode. Mater Sci Eng C 63:570-576. https:// doi.org/10.1016/j.msec.2016.02.079

13. Kaczmarska K, Brycht M, Leniart A, Skrzypek S (2017) Differential pulse voltammetric determination of an immunosuppressive drug teriflunomide on an edge plane pyrolytic graphite electrode. RSC Adv 7(42):26028-26036. https://doi.org/10.1039/ C7RA00407A

14. Dogan-Topal B, Bozal-Palabiyik B, Ozkan SA, Uslu B (2015) Electrochemical oxidation mechanism of anticancer drug nilotinib. Rev Roum Chim 60:467-475

15. Dordević JS, Kalijadis AM, Kumrić KR, Jovanović ZM, Laušević ZV, Trtić-Petrović TM (2012) Glassy carbon and boron doped glassy carbon electrodes for voltammetric determination of linuron herbicide in the selected samples. Cent Eur J Chem 10:1271-1279

16. Svancara I, Vytras K, Kalcher K, Walcarius A, Wang J (2009) Carbon paste electrodes in facts, numbers, and notes: a review on the occasion of the 50-years Jubilee of carbon paste in electrochemistry and electroanalysis. Electroanalysis 21:7-28

17. Svancara I, Walcarius A, Kalcher K, Vytras K (2009) Carbon paste electrodes in the new millennium. Cent Eur J Chem 7:598-656

18. Wiench P, Grzyb B, González Z, Menéndez R, Handke B, Gryglewicz G (2017) pH robust electrochemical detection of 4nitrophenol on a reduced graphene oxide modified glassy carbon electrode. J Electroanal Chem 787:80-87. https://doi.org/10.1016/ j.jelechem.2017.01.040

19. Smarzewska S, Pokora J, Leniart A, Festinger N, Ciesielski W (2016) Carbon paste electrodes modified with graphene oxidescomparative electrochemical studies of Thioguanine.
Electroanalysis 28(7):1562-1569. https://doi.org/10.1002/elan. 201501101

20. Smarzewska S, Guziejewski D, Leniart A, Ciesielski W (2017) Nanomaterials vs. amalgam in electroanalysis: comparative electrochemical studies of lamotrigine. J Electrochem Soc 164(7):B321B329. https://doi.org/10.1149/2.0221707jes

21. Yu H, Feng X, Chen X, Wang S, Jin J (2017) A highly sensitive determination of sulfite using a glassy carbon electrode modified with gold nanoparticles-reduced graphene oxide nano-composites. J Electroanal Chem 801:488-495. https://doi.org/10.1016/j. jelechem.2017.08.007

22. Beitollahi H, Tajik S, Mohammadi SZ, Baghayeri M (2014) Voltammetric determination of hydroxylamine in water samples using a 1-benzyl-4-ferrocenyl-1H-[1,2,3]-triazole/carbon nanotube-modified glassy carbon electrode. Ionics 20(4):571579. https://doi.org/10.1007/s11581-013-1004-0

23. Leniart A, Brycht M, Burnat B, Skrzypek S (2016) Voltammetric determination of the herbicide propham on glassy carbon electrode modified with multi-walled carbon nanotubes. Sensors Actuators B Chem 231:54-63. https://doi.org/10.1016/j.snb.2016.02.126

24. Robak J, Burnat B, Leniart A, Kisielewska A, Brycht M, Skrzypek S (2016) The effect of carbon material on the electroanalytical determination of 4-chloro-3-methylphenol using the sol-gel derived carbon ceramic electrodes. Sensors Actuators B Chem 236:318325. https://doi.org/10.1016/j.snb.2016.05.161

25. Sipa K, Brycht M, Leniart A, Urbaniak P, Nosal-Wiercińska A, Skrzypek S (2018) $\beta$-cyclodextrins incorporated multi-walled carbon nanotubes modified electrode for the voltammetric determination of the pesticide dichlorophen. Talanta 176:625-634. https:// doi.org/10.1016/j.talanta.2017.07.084

26. Afzali D, Padash M, Fathirad F, Mostafavi (2015) A determination of trace amounts of antimony(III) based on differential pulse voltammetric method with multi-walled carbon-nanotubemodified carbon paste electrode. Ionics 21(2):565-570. https:// doi.org/10.1007/s11581-014-1200-6

27. Mehmeti E, Stanković DB, Chaiyo S, Švorc L, Kalcher K (2016) Electrochemical determination of ajmalicine using glassy carbon electrode modified with gold nanoparticles. Monatshefte für Chemie - Chem Mon 147(7):1161-1166. https://doi.org/10.1007/ s00706-016-1741-7

28. Wang X, Li J, Wang T, Yu Z (2015) Voltammetric studies on the interaction of epinephrine with DNA base on a glassy carbon electrode modified with $\mathrm{Au}$ nanoparticles. Ionics 21(4):1105-1110. https://doi.org/10.1007/s11581-014-1243-8

29. Kelley V (2013) NanoScope Analysis 1.50 User Manual. Bruker Corporation, Santa Barbara

30. Wiberg KB (1965) Oxidation in organic chemistry. Academic Press, New York and London

31. Hammerich O, Lund H (2001) Organic electrochemistry. Marcel Dekker, New York and Basel

32. Balasubramanya RH, Patil RB, Bhat MV, Nagendrappa G (1980) Degradation of carboxin (vitavax) and oxycarboxin (plantvax) by Pseudomonas aeruginosa isolated from soil. J Environ Sci Health B 15(5):485-505

33. Mocak J, Bond AM, Mitchell S, Scollary G (1997) A statistical overview of standard (IUPAC and ACS) and new procedures for determining the limits of detection and quantification: application to voltammetric and stripping techniques (technical report). Pure Appl Chem 69:297-328

34. Shrivastava A, Gupta VB (2011) Methods for the determination of limit of detection and limit of quantitation of the analytical methods. Chron Young Sci 2(1):21-25. https://doi.org/10.4103/2229-5186. 79345

35. Psoma AK, PasiasIN IN, Bletsou AA, Thomaidis NS (2015) Development and validation of a multi-residue method for the determination of pesticides in chios mastic gum by QuEChERS and liquid 
chromatography-tandem mass spectrometry. Food Anal Methods 8(3):624-634. https://doi.org/10.1007/s12161-014-9930-7

36. Montes RHO, Dornellas RM, Silva LAJ, Squissato AL, Richter EM, Munoz RAA (2016) Amperometric determination of the insecticide fipronil using batch injection analysis: comparison between unmodified and carbon-nanotube-modified electrodes. J Solid State Electrochem 20(9):2453-2459. https://doi.org/10. 1007/s10008-015-3085-3

37. Ziyatdinova G, Salikhova I, Budnikov H (2014) Chronoamperometric estimation of cognac and brandy antioxidant capacity using MWNT modified glassy carbon electrode. Talanta 125:378-384. https://doi.org/10.1016/j.talanta.2014.03.039

38. Wan-Ling C, Ling L, Xue-Qing L, Kai-Li T, Fang F, Gong-Jun Y (2016) Determination of eriodictyol by a modified multi-walled carbon nanotube glassy carbon electrode. Anal Lett 49(10):1502-1512
39. Afkhami A, Ghaedi H, Madrakian T, Nematollahi D, Mokhtari B (2014) Electro-oxidation and voltammetric determination of oxymetholone in the presence of mestanolone using glassy carbon electrode modified with carbon nanotubes. Talanta 121:1-8. https://doi.org/10.1016/j.talanta.2013.12.047

40. Irandoust M, Haghighi M (2016) Electrochemical study and determination of dinitramine using glassy carbon electrodes modified with multi-walled carbon nanotubes. Electrochemistry 84(4):228 233. https://doi.org/10.5796/electrochemistry.84.228

41. Mehdi Ghoreishi M, Behpour M, Hajisadeghian E, Golestaneh M (2016) Voltammetric determination of resorcinol on the surface of a glassy carbon electrode modified with multi-walled carbon nanotube. Arab J Chem 9:S1563-S1568. https://doi.org/10.1016/j. arabjc.2012.04.009 